\title{
INVENTÁRIO DE DÍPTEROS (DIPTERA) NECRÓFAGOS NA UNIVERSIDADE ESTADUAL DE FEIRA DE SANTANA.
}

\author{
Jéssica Silva Santos ${ }^{1}$; Freddy Bravo ${ }^{2}$ \\ 1. Bolsista PIBIC/CNPq, Graduando em Ciências biológicas, Universidade Estadual de Feira de Santana, e-mail: \\ jesssicasantos_silva@hotmail.com \\ 2. Orientador, Departamento de Biologia, Universidade Estadual de Feira de Santana, e-mail: \\ fbravo@uefs.br
}

PALAVRAS-CHAVE: Moscas; Necrofagia; Inventário.

\section{INTRODUÇÃO}

Os dípteros necrófagos utilizam matéria orgânica em decomposição como fonte proteica ao menos numa fase de sua vida (Alves et al., 2014). Deste modo, o conhecimento taxonômico dessa fauna torna-se importante para estudos forenses, sanitários e médicos. Ciente da necessidade de um maior entendimento fisiológico e comportamental das famílias de dípteros e pela falta de informação na região e no município, já que existe apenas um estudo realizado em Feira de Santana. realizou-se este trabalho para avaliar e comparar sua riqueza, observando o padrão de atratividade exercido sobre moscas varejeiras por três diferentes substratos de origem animal (carnes de frango, peixe e bovina).

\section{MATERIAL E MÉTODOS}

O trabalho foi realizado em uma área urbana da cidade de Feira de Santana, o campus da Universidade Estadual de Feira de Santana (UEFS). Foram realizadas sete coletas, com quatro armadilhas iscadas com carne bovina, vísceras de frango e carne suína, seguindo a metodologia de Hwang \& Turner (2005). Cada ponto de coleta continham três armadilhas, de cada tipo de isca, repostas a cada 24 horas, durante os 3 dias de coletas. As análises estatísticas foram realizadas com o programa Bioestatic 5.3.

As coletas na UEFS foram realizadas em três pontos. Sendo o primeiro ponto próximo ao Laboratório de Biologia (LaBio), numa construção inacabada, onde cada armadilha ficou a 4 metros de distância de qualquer vegetação, as armadilhas foram fixadas na construção, onde a incidência solar era mais forte. $\mathrm{O}$ segundo Ponto foi próximo ao lago da pindoba, onde as armadilhas ficaram um metro de distância da estrada próxima ao lago, todas amarradas em arbustos . O terceiro ponto está localizado atrás da Biblioteca Central Julieta Carteado, diferencialmente dos pontos anteriores, neste as armadilhas ficaram numa vegetação fechada, com pouca incidência solar, devido a copa das árvores, amarradas nas arvores que estavam ali presentes. 


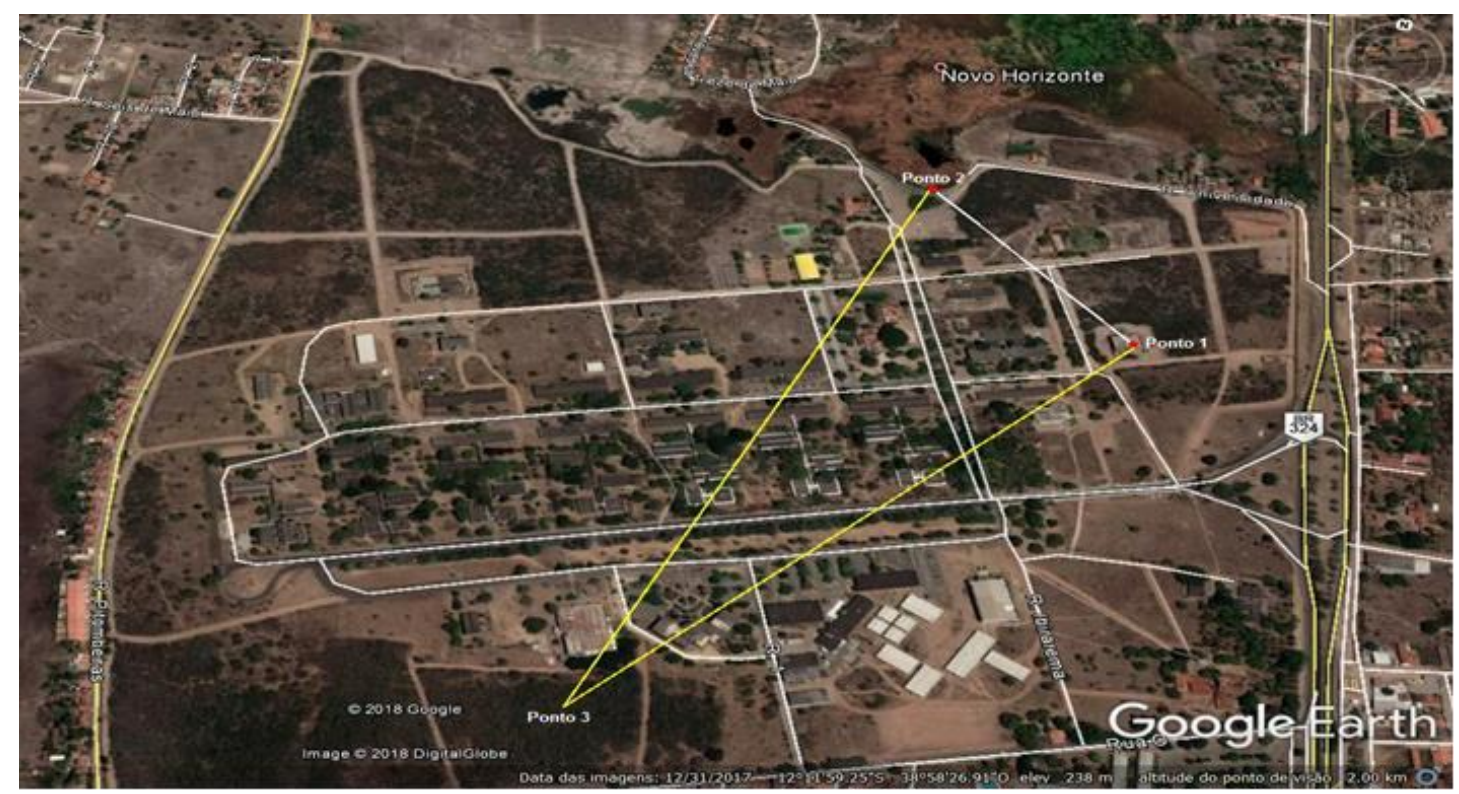

Figura 1: imagem de satélite de cada ponto de coleta regirada pelo Google Earth

\section{RESULTADOS E DISCUSSÃO}

Foram coletados 2.957 exemplares de doze famílias de dípteros caliptrados. As famílias coletadas neste estudo, na ordem de maior para menor em número de espécimes foram: Calliphoridae, Muscidae, Phoridae, Fanniidae, Sarcophagidae, Otitidae, Sepsidae, Drosopholidae, Dolichopodidae, Stratiomyidae, Sphaeroceridae e Psychodidae.

Em análise utilizando o teste $\mathrm{T}$ estudant, realizada comparando apenas a abundância e frequência das famílias encontradas demonstrou uma diferença significativa, tanto em relação ao ponto de coleta, quanto a atratividade da isca. O ponto 1 tem a maior frequência relativa por quantidade de espécimes, com 45,5\%, seguido do ponto 3 e por fim do ponto 2 (Tabela 1), demonstrando que fatores bióticos e abióticos do ponto 1 podem ser favoráveis para uma maior quantidade de espécimes de Dípteros. Quando analisada a quantidade de espécimes por família, Fannidadae, Calliphoridae, Muscidae e Sarcophagidae, consideradas cosmopolitas e antrópicas, aparecem sempre em maior quantidade no ponto $1 \mathrm{e}$ em menor quantidade no ponto 2 . O inverso ocorre nas demais famílias, possuindo uma maior quantidade no ponto $2 \mathrm{e}$ em menor quantidade no ponto 1. Apenas as famílias Sepsidae e Sphaeroceridae aparecem em maior quantidade no ponto 2 .

Fazendo uma análise segundo Freitas et al. (2000), Garcia et al., (2001), Gadelha (2009) e Silveira Neto et al. (1976), modificações e características bióticas e abióticas do ambiente influenciam diretamente nas espécies de insetos coletadas. Nos locais onde possuem fatores limitantes e uma maior competição intraespecífica, as famílias mais comuns aumentam suas populações e as raras apresentam baixo nível populacional. Explicando uma maior abundância de espécimes e uma menor diversidade no primeiro ponto, graças a fatores limitantes como uma maior incidência solar e distância da vegetação (árvores e arbustos) favorecendo as famílias: Calliphoridae e Muscidae. Em trabalhos realizados em Feira de Santana e no nordeste, estas famílias também se mostram como as mais frequentes e abundantes. No terceiro ponto, por conta da menor incidência de luz solar, graças à copa das árvores, e uma maior presença matéria orgânica vegetal, obteve uma quantidade absoluta pequena. 
Tabela 1: Família coletada em cada ponto de coleta com a sua classificação de abundância.

\begin{tabular}{|l|c|c|c|c|c|c|}
\hline & Ponto 1 & Ponto 2 & Ponto 3 & Total & Frequência relativa & $\begin{array}{c}\text { Classificação } \\
\text { de abundância }\end{array}$ \\
\hline Calliphoridae & 575 & 208 & 180 & 963 & 33,53 & Muito abundante \\
\hline Sarcophagidae & 88 & 66 & 64 & 218 & 7,6 & Comum \\
\hline Muscidae & 396 & 207 & 171 & 774 & 26,95 & Abundante \\
\hline Phoridae & 62 & 66 & 94 & 222 & 07,73 & Comum \\
\hline Fanniidae & 172 & 156 & 167 & 495 & 17,23 & Abundante \\
\hline Otitidae & 3 & 3 & 4 & 10 & 0,35 & Raras \\
\hline Sepsidae & 0 & 12 & 2 & 14 & 0,48 & Dispersas \\
\hline Drosopholidae & 5 & 21 & 37 & 63 & 2,2 & Comum \\
\hline Dolichopodidae & 1 & 9 & 31 & 41 & 1,42 & Comum \\
\hline Stratiomyidae & 3 & 0 & 3 & 6 & 0,21 & Raras \\
\hline Sphaeroceridae & 0 & 5 & 3 & 8 & 0,27 & Raras \\
\hline Psychodidae & 0 & 9 & 47 & 56 & 1,95 & Comum \\
\hline Total & 1305 & 762 & 803 & 2870 & 100 & - \\
\hline
\end{tabular}

Pela análise de variância (ANOVA) da frequência de captura de dípteros por iscas, em relação a abundância de espécimes, a isca com carne suína é a menos atrativa em relação às outras iscas. Porém, em relação a atratividade por abundância de espécimes, a atratividade das de vísceras de frango, a carne bovina e do peixe são equivalentes. Segundo os dados, a carne suína é a isca menos atrativa, sendo responsável apenas por $8,8 \%$ dos espécimes coletados (Tabela 2), porém é a que apresenta recepção a maior diversidade de famílias, além de maior abundancia das espécies classificadas como raras. O inverso acontece às outras iscas de carne bovina, estas atraíram mais espécies consideradas comuns e muito abundantes.

Tabela 2: Família coletada em cada tipo de isca com sua frequência relativa.

\begin{tabular}{|l|c|c|c|c|}
\hline & Carne & Frango & Peixe & Porco \\
\hline Calliphoridae & 402 & 248 & 277 & 37 \\
\hline Sarcophagidae & 118 & 54 & 39 & 4 \\
\hline Muscidae & 191 & 295 & 239 & 49 \\
\hline Phoridae & 41 & 65 & 71 & 45 \\
\hline Fanniidae & 83 & 146 & 204 & 62 \\
\hline Otitidae & 4 & 2 & 2 & 2 \\
\hline Sepsidae & 6 & 0 & 4 & 4 \\
\hline Drosopholidae & 12 & 10 & 18 & 23 \\
\hline Dolichopodidae & 12 & 11 & 11 & 9 \\
\hline Stratiomyidae & 0 & 0 & 2 & 4 \\
\hline Sphaeroceridae & 0 & 2 & 1 & 5 \\
\hline Psychodidae & 8 & 9 & 19 & 20 \\
\hline Frequência relativa & $30,55 \%$ & $29,65 \%$ & $31 \%$ & $8,80 \%$ \\
\hline
\end{tabular}

\section{CONSIDERAÇÕES FINAIS (ou Conclusão)}

- Foram coletados 2.957 exemplares de doze famílias de dípteros caliptrados.

- As famílias coletadas neste estudo, na ordem de maior para menor em número de espécimes foram: Calliphoridae, Muscidae, Phoridae, Fanniidae, 
Sarcophagidae, Otitidae, Sepsidae, Drosopholidae, Dolichopodidae, Stratiomyidae, Sphaeroceridae e Psychodidae.

- A isca com carne suína é a menos atrativa em relação às outras iscas, porém é a que apresenta recepção a maior diversidade de famílias.

- O inverso acontece às outras iscas de carne bovina, estas atraíram mais espécies consideradas comuns e muito abundantes.

- Em relação a atratividade por abundância de espécimes, a atratividade das de vísceras de frango, a carne bovina e do peixe são equivalentes.

- O ponto 1 tem a maior frequência relativa por quantidade de espécimes, com $45,5 \%$, seguido do ponto 3 e por fim do ponto 2 .

\section{REFERENCIAS}

ALVES, A. C. F., W. E. Dos Santos \& A. J. Creão-Duarte. 2014. Diptera (Insecta) de importância forense da região Neotropical. Entomotropica 29: 77-94.

HWANG, C., \& TURNER, B. D. (2005). Spatial and temporal variability of necrophagous Diptera from urban to rural areas. Medical and veterinary entomology, 19(4), 379-391.

FREITAS, A. V. L., Leal, I. R., Uehara-Prado, M., \& Iannuzzi, L. (2000). Insetos como indicadores de conservação da paisagem. Biologia da Conservação: Essências. São Carlos, RiMa Editora, 357-384.

GARCIA, Flávio Roberto Mello; CAMPOS, Jocélia Vargas; CORSEUIL, Elio. Flutuação populacional de Anastrepha fraterculus (Wiedemann, 1830)(Diptera: Tephritidae) na Região Oeste de Santa Catarina, Brasil. Revista Brasileira de Entomologia, v. 47, n. 3, p. 415-420, 2001.

GADELHA, Bárbara; FERRAZ, Adriana Cristina Pedroso; AGUIAR, Valéria Magalhães. A importância dos mesembrinelíneos (Diptera: Calliphoridae) e seu potencial como indicadores de preservação ambiental. Oecologia brasiliensis, v. 13, n. 4, p. 660-664, 2009.

SILVEIRA-NETO, S. et al. Manual de Ecologia de Insetos, Brasil. São Paulo. Ed. Agronômica Ceres, 1976.

Bioestat 5.3 [computer program]Disponível em URL: http://www. mamiraua. org. br/download/index. php? dirpath=. 